\title{
10.5005/jp-journals-10024-1161 CASE REPORT
}

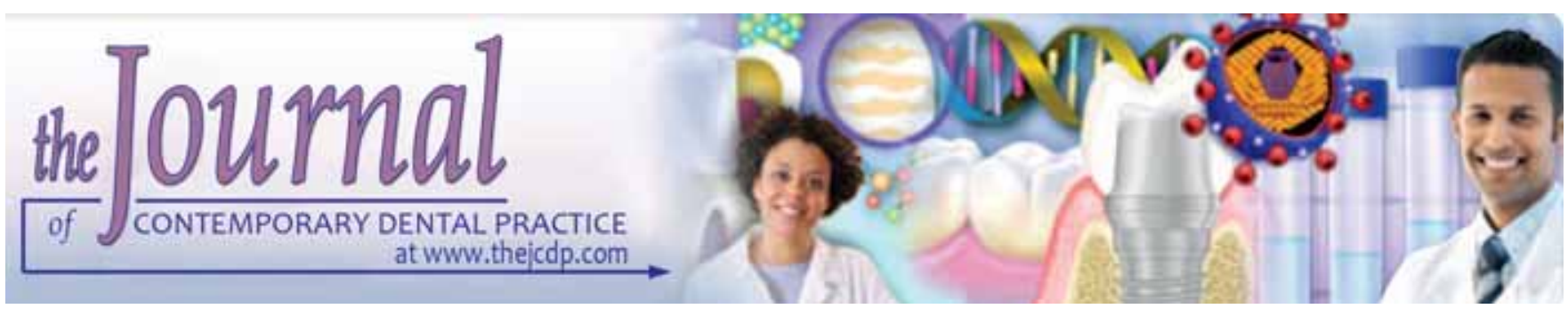

\section{Using the Self-etch Adhesives in Anterior Restoration}

\author{
Mateus Rodrigues Tonetto, William Kabbach, Edson Alves de Campos, Osmir Batista de Oliveira Junior \\ Sizenando de Toledo Porto Neto, José Roberto Cury Saad, Marcelo Ferrarezi de Andrade
}

\begin{abstract}
With the arrival of self-etch adhesives systems, there has been a rise in interest among clinicians, making it imperative for health professionals to have knowledge of the properties, characteristics, the association as well as the dental structures of these materials, in order to select them and use them correctly. The self-etch adhesive systems show good values of bond strength, microleakage and performance, and have therefore become an option in direct adhesive restorations. In the regard, this case study aims to describe the technique involving the use of selfetch adhesives system for direct restoration of anterior teeth.
\end{abstract}

Keywords: Esthetics, Self-etch adhesives, Restoration.

How to cite this article: Tonetto MR, Kabbach W, de Campos EA, de Oliveira J unior OB, de Toledo Porto Neto S, Saad J RC, de Andrade MF. Using the Self-etch Adhesives in Anterior Restoration. J Contemp Dent Pract 2012;13(3):421-424.

\section{Source of support: Nil}

Conflict of interest: None declared

\section{INTRODUCTION}

With the advent of adhesive dentistry, a major expansion of clinical indications occurred in both direct and indirect procedures. The dentin adhesives have been widely used in dental practice ${ }^{1}$ and new versions are constantly introduced, seeking greater simplification and improved clinical performance.

In order to optimize clinical procedures, the three steps (etching, primer and adhesive) conventional adhesives have gradually undergone evolution regarding the combination of components and the consequent simplification of the technique. New systems then appeared that combine the primer and adhesive in one step called 'the conventional two-steps', and the self-etch adhesives systems were launched later, where hybridization occurs simultaneously with the acid conditioning etching. ${ }^{2}$

The emergence of self-etch adhesives enabled the use of an adhesive strategy that reduces postoperative sensitivity where part of the smear layer is incorporated onto the adhesive layer and the smear plug lying at the mouth of the odontoblastic canals remains obliterating the passage of fluids and reducing significantly the dentin permeability, thereby contributing to a significantreduction in postoperative sensitivity.

The effectiveness of self-etch adhesives systems in the dentin has been evidenced in research studies. ${ }^{3-5}$ In this technique, previous acid etching is not performed, in this way, as the self-etch adhesives come into contact with the dentin substrate, acid monomers are then released which not only demineralizes the dentin but also allows the adhesive penetration so, that entire etched area is filled with the adhesive, i.e. there are no areas in which the collagen fibers are exposed by a demineralization greater than the penetration capacity of the adhesive. Thus, the risk of the occurrence of degradation of the nonencapsulated collagen area is reduced and a hybrid layer of minor thickness is produced, it is more regular, though. ${ }^{6}$

The values of the bond strength of the dentin are comparable to those of three-steps, however, the same does not occur in the enamel, because of the due to tamponing lower conditioning power of the acid primer. ${ }^{7}$ The high mineral content present in the enamel self-limits the demineralization forming a microretentive standard much lower than that obtained with $37 \%$ phosphoric acid etching. ${ }^{8}$ For this reason, scientific research studies ${ }^{9,10}$ suggest the phosphoric acid etching only in the enamel, in order to create microretentive pattern, followed by the application of selfetch adhesives throughout the cavity.

Although there is no consensus on the use of self-etch adhesives, this is being recommended to reduce the sensitivity of the technique and add clinical efficiency, and thus, reducing labor time and proving to be satisfactory. Clinical follow-ups tend to be important for better acceptance and accreditation of the scientific community. 
Having said above, this case study aims to describe the technique of using a system of self-etch adhesives for direct restoration of anterior teeth.

\section{CASE REPORT}

A male patient aged 13, sought dental care, reporting pain and discomfort in the upper left lateral incisor (tooth 22). It was observed following the clinical and radiographic examination that the tooth had caries and the suggestion made $w$ as to remove the caries and restorative treatment in the dental element opting for performing direct composite resin restoration using single-step self-etch adhesives system A dper easy one (3M ESPE).

Original photograph was then taken (Fig. 1) where the color selection was performed with the V ita Classical scale, in which A 2 was the predominant color. The waxing of the diagnostic model was carried out afterward (Fig. 2), in order to facilitate the insertion of restorative material from the palate guide made of silicone condensation according to the anatomy of the tooth in question.

A fter prophylaxis and absolute isol ation, the patient was anesthetized, made access to carious lesions using a diamond tip in rapid rotation, we then subsequently removed the decayed tissue with multilayered tips at low speed and size compatible with the cavity (Fig. 3). With the aid of a millimeter probe, we noted the presence of unsupported enamel dentin (Fig. 4), where it was removed using the coarse-grained disk named Sof-L ex Pop-on so as to prepare the bevel (Fig. 5).

With the neighboring teeth protected with a teflon tape, the selective acid etching was carried out in the enamel as

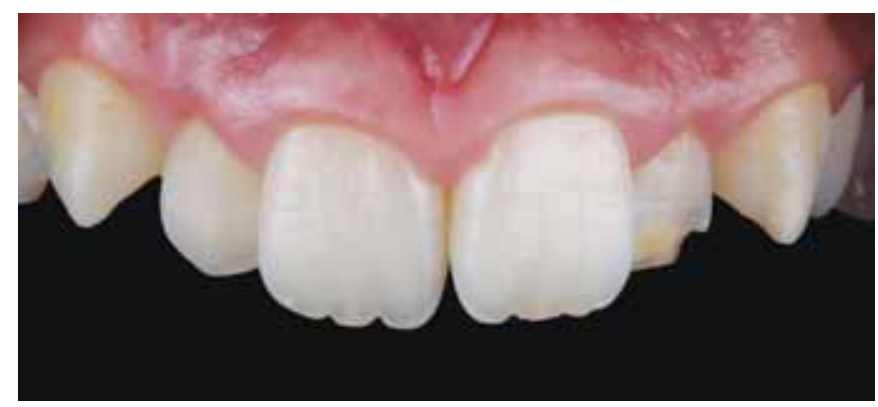

Fig. 1: Front view of the upper arch

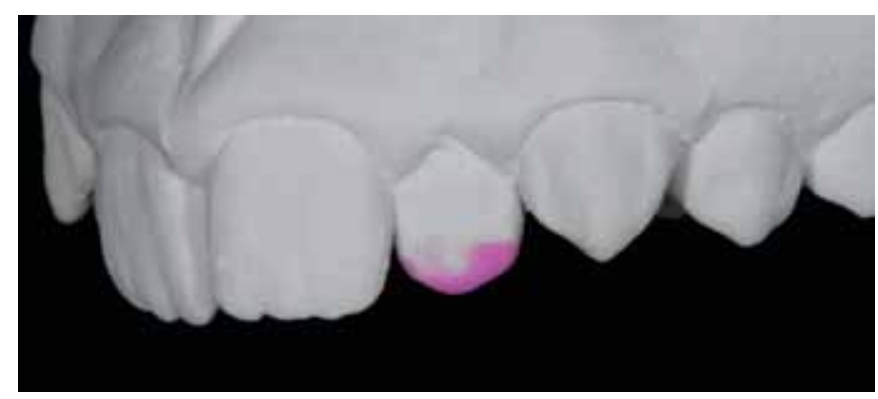

Fig. 2: Front view of the study model waxed recommended in the literature ${ }^{8,9}$ for the utilization of selfetch adhesives, applying phosphoric acid at 37\% (Fig. 6) for 15 seconds. A fter that, the acid was removed with a jet of water and dried with absorving pad. The application of self-etch adhesives Adper easy one (3M ESPE) was done following the manufacturer's recommendations. The

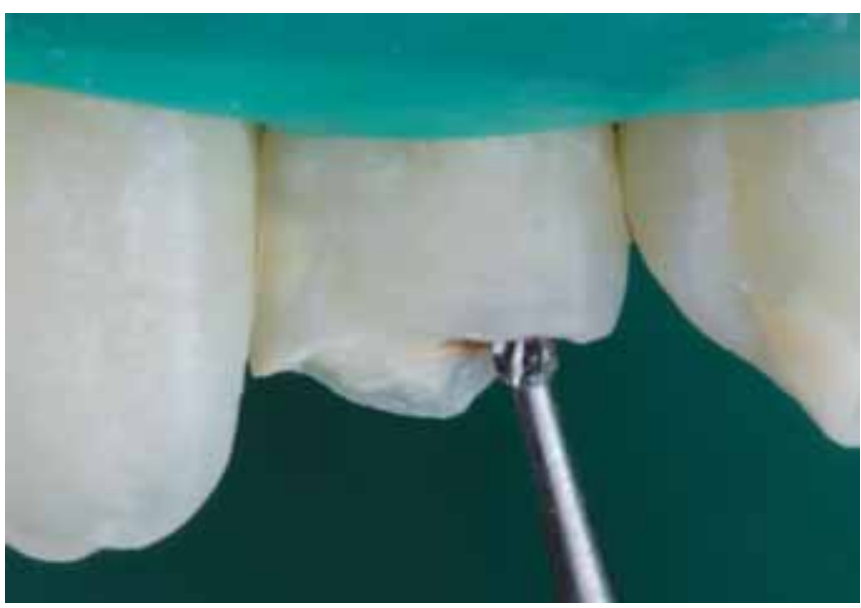

Fig. 3: Removing the decayed tissue with multilayered tips at low speed and size compatible with the cavity

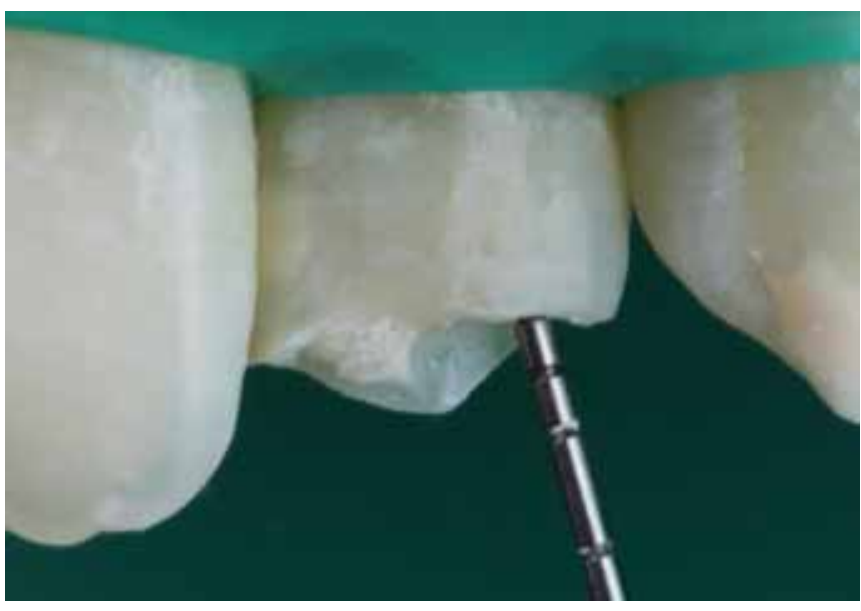

Fig. 4: Utilization of millimeter sonata to verify unsupported enamel

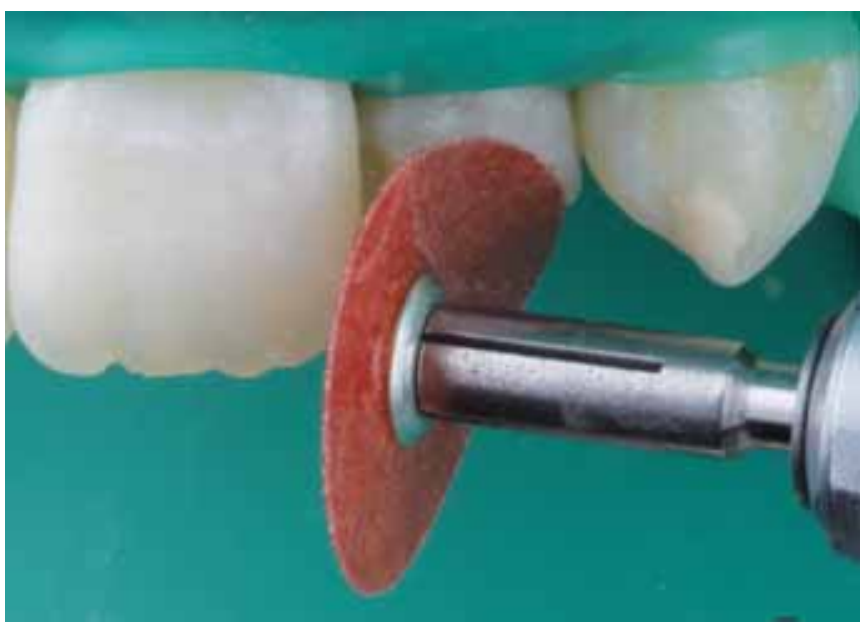

Fig. 5: Using the coarse-grained disk sof-lex pop-on to prepare the bevel and to remove the unsupported enamel 
adhesive was applied actively for 20 seconds (Fig. 7), and in order to evaporate the solvent, the jet of air was lightly used for 5 seconds, completing the stage with photopolimerization for 10 seconds.

In the restorative procedure, increments of composite resin on enamel shade A 2 (Z350 XT-3M ESPE) were inserted into the guide initially made of silicone so, as to restore the palatal wall of the tooth (Fig. 8). The silicone guide was brought into position (Fig. 9) and light cured for 40 seconds. Having removed the silicone guide, composite resin in increments of dentin shade A 2 (Z350 XT-3M ESPE) were inserted to return the lost dentin. $A$ thin layer of resin with average opacity A2B (Z350 XT-3M ESPE) was accommodated in the region of the enamel were essential care was taken to leave room for the last layer of resin. For the reanatomization of the enamel, resin in increments of enamel shade A 2 (Z350 XT-3M ESPE) were used, and polymerization was carried out for 40 seconds.

In the next session, the patient returned for finishing and polishing to be done. To this end, we used multi-rolled

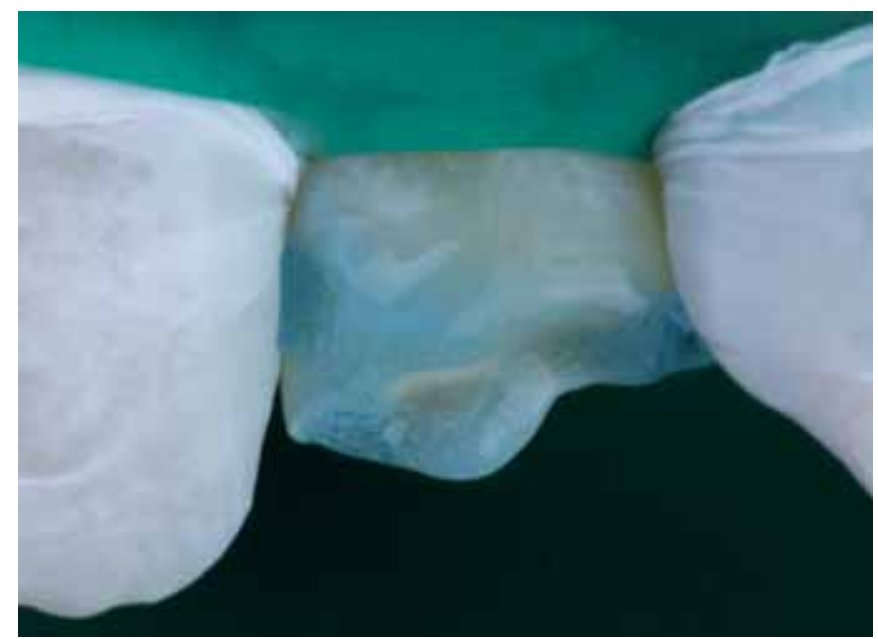

Fig. 6: Applying phosphoric acid at $37 \%$ for 15 seconds in the enamel

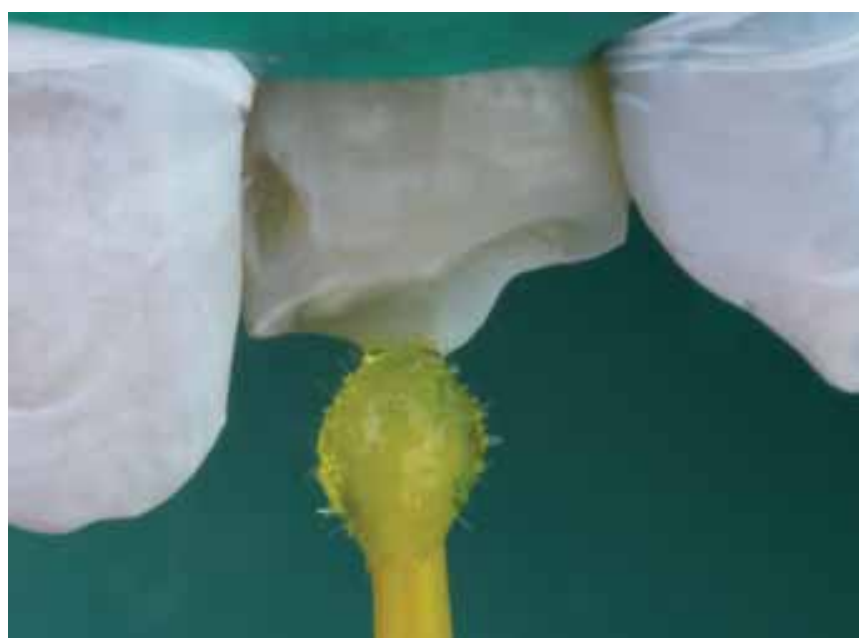

Fig. 7: Adhesive been applied actively for 20 seconds edges and abrasive disks (Sof-Lex Pop-On 3M ESPE), following the order of the largest to the smallest grain. A Iso, before the last abrasive disk of the sequence, $\mathrm{FF}$ points were used, producing light ends in the enamel, providing it with a natural shape (Fig. 10).

\section{DISCUSSION}

Conventional adhesive systems can produce high forces of adhesion between resin and dentin, but reports show that some factors may influence their performance. A n excessive etching of dentine produces weak union because the demineralized collagen fibers are not completely saturated by the resin. ${ }^{11}$ The existence of a layer of collagen decalcified and not impregnated with resin as the base of the hybrid layer can weaken the union dentin/resin. The intrinsic presence of water on the dentin and solvent, such as ethanol and acetone in the adhesive can affect the polymerization of the resin composites in the hybrid layer. ${ }^{12}$

With the evolution of adhesive systems, manufacturers have replaced the conventional systems with the single-step

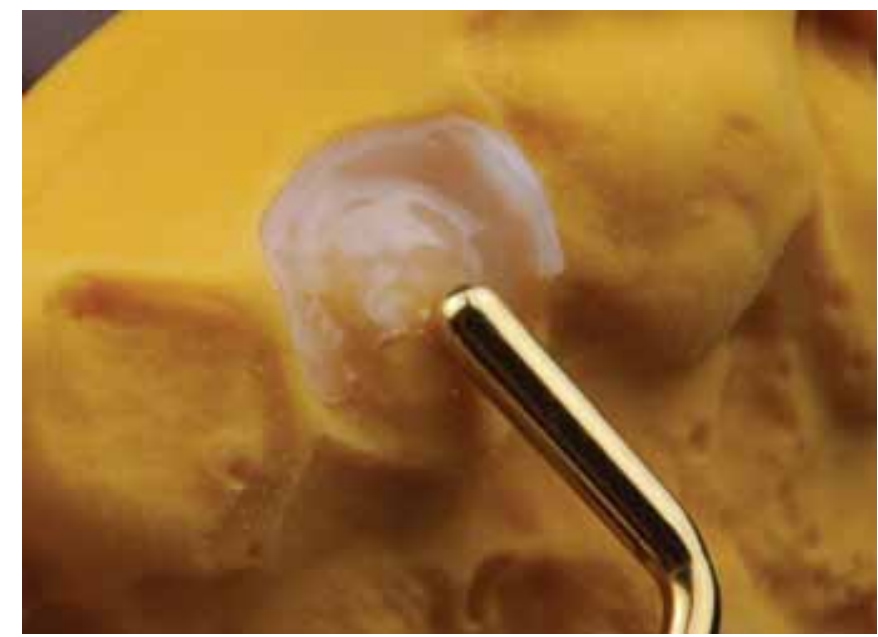

Fig. 8: Increments of composite resin A2E (Z 350 XT-3M ESPE) were inserted into the guide initially made of silicone

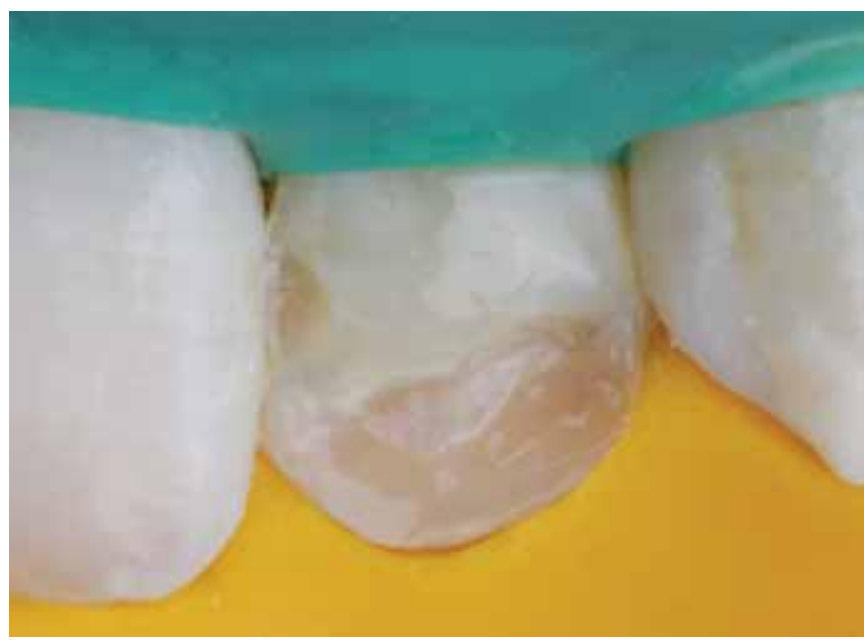

Fig. 9: Silicone guide into position 


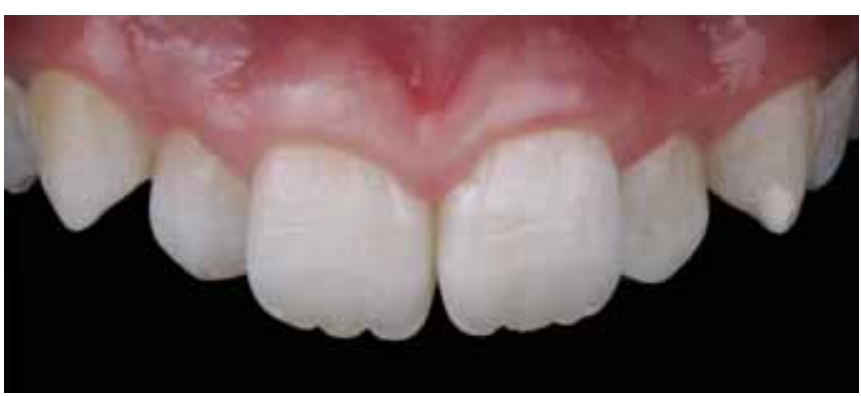

Fig. 10: Front view of the case completed

ones. These stickers contain in their composition selfetching primers, where hybridization occurs simultaneously with the conditioning, in a single-step. ${ }^{13-15}$ Thus, when using the self-etch adhesives, there is no need to condition, wash and dry, eliminating the risk of over-etching the dentin, and letting it become excessively moist.

The biggest problem of the self-etch adhesives has to do with the enamel because they have weak acids in their composition, ${ }^{16}$ leading to an unsatisfactory effect in terms of adhesion, so some manufacturers recommend the initial use of phosphoric acid on the enamel for better effectiveness as said in the case report.

\section{FINAL CONSIDERATIONS}

The process of adhesion to tooth structures has evolved considerably in recent years, and the self-etch adhesives systems have become an option in direct adhesive restorations. For a better efficacy of this system, we recommend an adjustment in the technique with acid etching enamel with $37 \%$ phosphoric acid prior to the application of the system self-etch adhesives.

\section{REFERENCES}

1. Dinelli W, Fernandes RV, A ndrade M F, Guimaraes NC, B evilacqua FM. In vitro study of staining agents effects on optical properties of esthetic restorative materials. Journal of Dentistry and Oral Hygiene 2010;2(4):34-37.

2. Bouillaguet S, Gysi P, Wataha J C, Ciucchi B, Cattani M, Godin C, et al. B ond strength of composite to dentin using conventional, one-step, and self-etching sdhesive systems. J Dent 2001;29(1):55-61.

3. Al-Ehaideb A, M ohammed $H$. Shear bond strength of one 2 bottle dentin adhesives. J Prosthet Dent 2000;84(4):408-12.

4. Takahashi $A$, Inoue S, Kawamoto $C$, Ominato R, Tanaka T, Sato $Y$, et al. In vivo long-term durability of the bond to dentin using two adhesive systems. J Adhes Dent 2002;4:151-59.

5. Y oshida Y, Nagakane K, Fukuda R, N akayama Y , Okazaki M, Shintani $H$, et al. Comparative study on adhesive performance of functional monomers. J Dent Res 2004;83:454-58.

6. Peumans $M, K$ anumil LI, De M unck JP, V an L anduyt $K$, A mbrechts $P, V$ an Eerbeek $B$. Clinical effectiveness of contemporary adhesives. Dent M ater 2005;21:864-81.

7. Y oshiama M, M atsuo T, Ebio S, Pasheley D. Regional bond strengths of self-ecthing/self-priming adhesive systems. J D ent 1998;26(7):609-16.
8. M iguez PA, C astro PS, N unes M F, W later R, Pereira PN . Effect of acid-etching on the enamel bond of self-ecthing systems. J Adhes Dent 2003;5(2):107-12.

9. Marquezini Jr L, Pereira LCQ, Carvalho RM, Tay FR, Pashley DH. Effects of pré-etching on the durability of bond strengts of self-etching adhesive to ground enamel. J Dent Res 2003;82 (Sp Issb): A bstr. 862.

10. Van Landuyt $K L$, De M unck J, Snauwaert J, Coutinho E, Itevin A, Y oshida $Y$, et al. M onomer-solvent phase separation in one-step self-etch adhesives, J Dent Res 2005;84(2):183-88.

11. Nakabayashi N, Kojima K, Masuhara E. The promotion of adhesion by the infiltration of monomers into tooth substrates. J Biomed M ater Res 1982;16(3):265-73.

12. M iyazaki $\mathrm{M}, \mathrm{O}$ nose $\mathrm{H}$, lida $\mathrm{N}, \mathrm{K}$ azama $\mathrm{H}$. Determination of residual double bonds in resin-dentin interface by Raman spectroscopy. Dent M ater 2003;19(3):245-51.

13. Spencer $P, W$ ang $Y$, W alkerl M P, W ieliczka D M , Swafford JR. Interfacial chemistry of the dentin/adhesive bond. J Dent Res 2000;79(7):1458-63.

14. W ieliczka DM , K ruger M B , Spencer $P$. Raman imaging of dental adhesive diffusion. A ppl Spectrosc 1997;51(11):1593-96.

15. V an Landuyt $K L, K$ anumilli $P$, De M unck J, Peumans $M$, L ambrechts $P, V$ an $M$ eerbeek $B$. B ond strength of a mild selfetch adhesive with and without prior acid-etching. J Dent 2006;34(1):77-85.

16. M artins GC, Franco A PGO, Godoy AP, M aluf DR, Gomes J C, Gomes OM M . A desivos Dentinários. R GO 2008;56(4):429-36.

\section{ABOUT THE AUTHORS}

\section{Mateus Rodrigues Tonetto (Corresponding Author)}

M aster's Student, Department of Restorative Dentistry, Pio Correa Pine A venue, A pt 65131b, M el hado A raraqura SP, CEP: 14807-031 UNESP A raraquara (FOAR) Brazil, Phone: 1681354693 e-mail: mateus-tonetto@foar-unesp.br

\section{William Kabbach}

Doctoral Student, Department of Dentistry, UNESP, A raraquara (FOAR), São Paulo, B razil

\section{Edson Alves de Campos}

Teacher, Department of Restorative Dentistry, UNESP A raraquara (FOAR), São Paulo, B razil

\section{Osmir Batista de Oliveira Junior}

Teacher, D epartment of Restorative Dentistry, UNESP A raraquara (FOAR), São Paulo, B razil

\section{Sizenando de Toledo Porto Neto}

Professor, D epartment of R estorative Dentistry, UNESP, A raraquara (FOA R), São Paulo, B razil

\section{José Roberto Cury Saad}

Professor, Department of Restorative Dentistry, UNESP, A raraquara (FOA R), São Paulo, B razil

\section{Marcelo Ferrarezi de Andrade}

Teacher, Department of Restorative Dentistry, UNESP A raraquara (FOAR), São Paulo, B razil 